\title{
Power, politics and everyday life: the local rationalities of social movement milieux
}

\section{Introduction: the cultural roots of political conflict ${ }^{i}$}

Everyday language readily identifies social movement activity - campaigning, protesting, holding meetings, issuing statements - as "politics"; perhaps not in the sense of parties and parliaments, but politics none the less. Much academic literature shares this view of social movements as "politics by other means", from resource mobilisation and political opportunity structure approaches to analyses of social movements as expressions of economic interests (for an overview, see Diani 1992a). It is interesting, then, that precisely in continental Europe, where contemporary social movements have arguably made the greatest impact on the party system and engaged in the sharpest confrontations with the state, theorists have tended more and more to stress the cultural aspects of social movements.

One theme sees movements as rooted in specific sociocultural milieux: largescale, ñlifestyleî responses to structured experience of inequality, with differing issues and priorities (Vester et al. 1993, Hradil 1987); and local ñmovement milieuxî within these, and the shifts in class habiti that can be identified between generations here (MÜller 1990). Another approach identifies a shared culture as a structural element of social movement activity: as an identity enabling the networks between organisations, groups and individuals that make up a movement (Diani 1992a, 1992b); or as ñcognitive praxisî combining worldview, issue-specific knowledge and modes of organisation (Eyerman and Jamison 1991). Thirdly, social movements can be analysed as cultural challenges: movements may struggle to control the cultural definition of ñhistoricityî, societal self-production (Touraine 1981, 
1985); their structural form may itself be a symbolic message to the wider society (Melucci 1985, 1989, 1992); or there may be a division between ñpoliticalî and ñculturalî movement strategies (Raschke 1985).

The "social movements" problematic could then be restated with an emphasis on the culture of movement milieux as the source of mobilisation, of the internal culture of movement activity, and of wider challenges to the social order. The need is then to locate particular forms of engagement with power and the political within particular sociocultural formations. One possible response is the critical theory analysis of movements as defending the communicative rationality of the lifeworld against colonisation by capitalist and state rationalities (Habermas 1984, 1987). Yet while particular, "decommodified" lifeworlds are identified as crucial (Offe 1985), it is a long way from a universal communicative rationality to the specific cultural logics of contemporary lifeworlds. If instrumental rationalisation had specific roots in Calvinist soteriology, so communicative rationalisation must have particular beginnings.

A partial remedy is Eder's $(1985,1993)$ analysis of contemporary movements as expressing the habitus of the petite bourgeoisie and its struggle to impose its cultural definitions; yet this habitus is ascribed rather than examined, read off from the structural position of the class - and unsurprisingly contradicted by the Hannover project's findings of significant transformations in class habitus within movement milieux (MÜller 1990, Vester et al. 1993). Both critical theory and Eder's approach offer to relate movement activities to movement milieux, but both fail to take account of the cultural specificity of the latter. The issue is then how to theorise, and research, such specificity.

\section{The concept of local rationalities}


What is needed is a heuristic concept that does not already assume a specific cultural content. Such a concept would have to make it possible to link the culture of movement milieux with the forms of activity and challenges raised by social movements; avoid an a priori exclusion of the political or the cultural; and enable an empirical engagement with the cultural specificities of actual movement milieux. I want to suggest the concept of "local rationalities" as a means of doing this.

The specific cultures of movement milieux are ñlocalî, contingent in relation to an abstract theory of modernity yet not necessarily in relation to actual societies. To stress contingency is to avoid the purely rationalist imputation of a particular culture to such milieux on the basis of abstract considerations, and to encourage the realist attempt to relate theory to the phenomenal world (McLennan 1981) or, less grandly, to keep the question open.

"Rationality" then indicates the ontological level on which this culture is being sought. By analogy with the typologies of rationality developed by Weber (1984) and Habermas (1984), it implies a formal characteristic about the way we make sense of and engage with the world which is capable of being generalised and taking on a life of its own. Thus the formal principle of a rational calculation of which means are best suited to achieve given ends enables that particular rethinking of the world we call modernity. Starting from a specific problem in a specific cultural milieu, it could be generalised to encompass all aspects of action and be used to restructure any other milieu. Thus I am looking, within specific movement milieux, for formal elements in the way people act, talk and make sense of the world which can be generalised to restructure many areas of activity, notably linking everyday life with movement action.

\section{Elements of local rationalities}


The discussion which follows is drawn from research in progress in Dublin "movement milieux". I am researching in particular a network formed inter alia in London squats, Dublin crashpads, a student occupation and antinuclear and ecological organisations, which has in turn formed a context for a variety of alternative "political" and "cultural" projects and experiments, such as:

- Political projects, such as anarchist and green groups, street theatre, student politics, direct action, etc.;

- Experimentation with living forms, in particular shared houses, squats and "crashpads";

- Economic experiments, such as cooperatives, alternative bookshops, LETS systems, etc.;

- Experimentation with sexual relationships, including bisexual, open and multiple relationships;

- Experimentation with drugs, in particular hash, acid and mushrooms;

- Cultural experiments, such as alternative music, , Rainbow Gatherings, pagan and occultist rituals and groups, etc.

This paper draws on five interviews of my series with members of this network: three men and two women, all in their mid- to late-twenties when interviewed. For reasons of internal privacy and external protection all names have been changed. Four are Irish, one is a European immigrant; class backgrounds range from skilled working class to professional, and occupations at the time of interview included unskilled worker, residential care worker, research student and computer programmer.

The "local rationalities" of this network, as they appear above all in interview material, stress specific forms of autonomy and reflexivity: autonomy as selfdevelopment and what could be called "lifeworld reflexivity" as the 
suspension of the "taken-for-granted" attitude, and the willingness to make changes, in all areas of activity.

\section{Autonomy as self-development}

The principle of autonomy is of course not a new one within modernity (Wagner 1994). Yet most modern formulations take the self for granted. Thus instrumental rationality treats both the self and its goal as assumptions, and enquires merely what the most effective way of getting from $\mathrm{A}$ to $\mathrm{B}$ is. Even in its most hedonistic forms, possessive individualism is simply a special case of this approach. Romanticism, commonly ascribed to movement milieux, assumes that there is a natural, pre-given - and already known - self, albeit obscured by conventions and civilisation, and that the issue is one of placing this natural self first. Yet the logic of autonomy presented within this lifeworld places the self in question, as an open-ended project, something to be constructed or transformed. Thus participants make comments along the following lines:

Ciar $\$ n$ is ambitious within himself, it's himself that he wants to develop, not a career or any of that kind of stuff. (Josh)

Another participant speaks of

People who do all kinds of odd and extremely innovative things, an awful lot of people whose top priority is sorting their head out, or whose top priority is something along the lines of enlightenment. (Ruth)

In this context, the pursuit of autonomy and self-realisation is explicitly contrasted to the goal-rational pursuit of material interests:

It comes back to this idea that the way in which people perceive ambition as not a material ambition, which again links back to the ideas about people's attitude to property and that. Whilst they have fuck all of it, I don't think that is entirely responsible for their attitude. 
The development is sort of personal development, it's not material development. So the idea of going away to make money isn't really, you're not going to impress anybody, really. 'Oh wow, he's earning fuckloads of money, good for him, so what?' (Josh)

The main theme is that of moving away from instrumental approaches, for example, that of seeking the best available employment, towards an explorative approach to one's own life. This explorative sense is underlined by the relatively weak articulation of the nature of the alternatives and how to get there: it is not simply choosing an alternative strategy to achieve preexisting goals. Rather, goals are something to be revised along the way. Similarly, instead of identifying with a fixed self (whether the given self of instrumentalism or the "true" self of romanticism), the self is seen as something to develop. One takes a distance from "the self" in order to change it or observe it changing.

\section{The politics of autonomy}

It is then in keeping with this logic that the instrumentally rational pursuit of politics in the narrow sense is often rejected outright in the name of autonomy:

LC: Groups are bad things?

- Yeah, kind of limiting. If you try and set up anything a lot of these people will just go 'I'm not interested'. You know, if they happened to be somewhere and something happened they'd go for it, but anything organised they're not interested in, anything that sounds remotely political they don't want to know.

LC: Why is that?

- Don't believe in politics, a lot of people just find it boring, or completely pointless, or they live their life the way they want to and they live and 
let live, if other people want to get into politics. You know, it would kind of be 'if you're into politics that's your trip, whereas me, I just want to wander round and play guitar.' (Ruth)

If politics is "your trip", it is simply one way among many of pursuing the project of self-development. Alternatively, it may be a means of defending the free space required for the pursuit of autonomy:

Politics is the mechanism by which decisions that affect my life are made, therefore if I wish to have any control over my life I must have an interest in politics, but it is not the driving force of my life. (Josh)

Thus political activity takes its place as one lifeworld interest among others, to be handled with tolerance. Speaking of a couple of heavily committed activists, for example,

People know what Se $\$ n$ and Muireann are up to, but they're not very strongly influenced, and that's an example of Se $n$ and Muireann being part of that group, coming from that group, and finding their own space [...] But Se $\$ n$ and Muireann didn't ram it down anybody's throat, and nobody tried to make them conform to what was going on. (Josh)

This tolerance, in fact, appears as a condition of autonomy:

There is a sort of laid-back attitude which allows people to do their own thing and is very very tolerant of people's individuality and people doing their own thing and coming and going as they please. (Josh)

Thus movement activity can form part of most of an individual's project of self-development, and it takes its place within the local rationalities of the network on this basis. This logic of autonomy as self-development, however, has immediate effects in relation to the forms of politics which can take root in it, as well as in the attitudes taken to the political.

On the one hand, political forms conducive to this type of autonomy are preferred. Thus the direct democracy of the squat or the occupation and 
their articulate counterpart in anarchist organising or the network of intersecting projects and its articulate counterpart in green politics represent two possibilities of "doing" politics. Similarly, the immediate, lifeworld-bound activity of demonstrations, direct action, the local project or the once-off event are preferred to more hierarchical political forms, whether of largescale organisation or of clientele-building, whose only possible meaning is instrumental and whose operation runs directly counter to the logic of autonomy:

I think the fact that these people have the laid-back attitude of allowing people to do their own thing is a mechanism which allows very strong personalities and very strong individuals to be able to interact with each other without stomping on each other's toes, and the sorts of ambitions that those people have, and the way in which they allow that ambition to be fulfilled, doesn't involve getting a group of people to centre round you. (Josh)

On the other hand, as we have seen, the political is itself relativised, as one means of pursuing or defending the project of self-development among others. As Melucci has said, activists engage in movement activities on the basis that it has meaning for them, not in terms of its instrumental value: "if it doesn't make sense to me, I am not participating; but what I do also benefits others" (1989: 49). At the same time, from either a Habermasian or a Foucauldian point of view, this attitude is itself a form of resistance to the instrumental logic of the political system: participants see the defence of personal, psychological and group free space and independence as primary, and participation in more organised "political" ways of realising this goal is always provisional. Thus local rationalities themselves position the political and allocate it a very specific place in terms of the pursuit of autonomous self-development. As we shall see, this is also true in relation to reflexivity.

\section{Lifeworld reflexivity and movement milieux}


Implementing such a project of autonomous self-development necessarily implies a reflexive attitude to social relations, and more specifically an active reflexivity, in the sense of the creation of meanings and practices which not only defend the "free space" necessary for the project but directly enable this self-development, and develop the projects of the self as they move from the theoretical into the practical.

Movement milieux, then, are reflexive milieux, and we can speak with Lash (1994a) of a lifeworld reflexivity along with self-reflexivity or institutional reflexivity, and attempt to locate movement activities within this logic. In particular, if "self-development" is to have any social reality, it must mean a change of the social relations within which people experience themselves and are confirmed in their identity. This implies a questioning of given social relations and a distancing from them; a search for alternative possibilities; and an exploration or experimentation with projects, including movement activities, which might enable the realisation of new "identities" or a longerlasting project of self-development. This move away from unreflexive lifeworlds is immediately political, in the sense of raising questions of power and control, but not necessarily in the sense of an engagement with the institutions of political intermediation (Melucci 1992).

\section{Distancing from unreflexive lifeworlds}

A logical prerequisite for any developed form of reflexivity is a certain measure of distancing from the "normal" and "taken-for-granted" assumptions of unreflexive lifeworlds. At its most basic, this appears as a personal attempt to find another path:

People [in the Dublin suburbs] seemed to be content with just kind of shambling along, and into secondary school and out the other side, into a job, and not losing touch with their friends in the pub every night of the weekend, but that wasn't enough for me. I was looking for 
something other and massively more, something to quench a deeper thirst for life. Like zombies, those people. (Mark)

This distancing operates in relation to the normal assumptions of people's class backgrounds:

Even before I went to college I went 'I want to do a sort of liberal arts thing that isn't going to qualify me for one thing, so I can't just be pushed into doing a HDip [teaching qualification]', and a lot of people said 'Oh, so you're going to be a teacher'. I said, 'No, I don't want to be a teacher.' I just wanted to leave Dublin for a while, do a lot of travelling, I'm grand. (Ruth)

Most participants failed in one way or another to take the instrumental attitude to education demanded by conventional Irish assumptions about its role in providing secure employment. Similarly, many avoided the "obvious" strategy of taking the available opportunities in e.g. computers, translation or the music business. While this distancing from class assumptions is very general, there is also an ethnic distancing for a number of participants:

There are things you know, but they still have to be right in front of you to be obvious, like I always knew that the entire world wasn't white, Irish, all the rest of it, you know that all these other cultures exist, but it's when you actually meet them that it's different, because they live their whole life in a totally different perspective to you, which is great. (Ruth)

Lastly, there is a distancing (for women at least) in relation to dominant gender assumptions:

- You know, sometimes I wish 'Why'm I not like my sister?', you know? [laughs] Why do I make life so hard for myself? Why don't I just want a normal job, and a husband, and two kids, and a house, and two cars?

LC: Well, why? 
- I don't know why, I just don't. [laughs] I just find it immensely boring.

(Katya)

As this last comment indicates, these are real choices that have to be made, and continually remade, within individuals' lives ("Why do I make life so hard for myself?"); but they are also made in relation to an alternative habitus ("I just find it immensely boring"). Distancing is not an easy exercise; and it depends crucially on the availability of local rationalities within which it makes personal and emotional sense. This very often implies a physical distancing towards known movement milieux:

People go [to San Francisco] from all over the world. Usually people looking for something, or people who are too weird for the small town that they live in. I mean, people come from Ohio, the Midwest, and from places where they're just too freaky for where they live, or they can't handle how racist where they are is. A lot of people say they couldn't deal with how racist it is. (Ruth)

This suggests something of the working of this conflict between lifeworlds: the pursuit of autonomy leads both to rejection by unreflexive lifeworlds ("too weird", "too freaky") and to rejection of those same lifeworlds ("they can't handle how racist it is"), pushing people towards movement milieux. Along with the usual forms of Irish emigration, it is noticeable that this lifeworld also includes a number of people who have emigrated to Ireland from western Europe, as well as a number of Irish people who have returned from significant periods of time in the movement milieux of e.g. London, Paris or Berlin. A similar clash between unreflexive and reflexive lifeworlds is evidenced in this returnee's perspective:

So after I got back from there, I ended up in college, which was like being right back in secondary school again, which was about as far removed from where I'd been as I could have got at the time. So I wasn't very well acculturated, I kind of disacculturated myself somehow from 
all that kind of thing, I didn't relate to it very well. I'd lost all fear of loss of social prestige or position, all the subtle motivations for the middleclass Dublin life, they're all based on social position, standing and material comfort. All those kind of values I kind of shed [abroad]. (Mark)

The reflexive (re-)creation of self starts from deliberate acts of distancing from one's lifeworld background, but for its stabilisation requires an association with the alternative rationalities represented by movement milieux.

\section{The uses of other movement milieux}

If this association cannot be face-to-face, mediated participation in other milieux which relativise the here-and-now by making present other cultural possibilities can be an important building block for local reflexive milieux. These are rarely seen as something to be imitated verbatim; rather, they are used as a tool for opening up a sense of possibility with regard to one's own life - in other words, to enable reflexivity. Thus one participant stresses

the fact that [those involved] are very well read and are involved in, interested in most things. (Josh)

These are not just individual attributes, but relate to a reflexive habitus of (literally) reading other ways of life as a means of gaining distance from one's own background and of creating new possibilities.

So, for example, the American counter culture of the 1960 s is critically examined as a sort of map of the territory opened up by the reflexive perspective:

What I thought happened in the sixties was that people started thinking very differently, not for the first time ever, but that they had this wealthy class of people who should have been happy as flowers, [...] 
and instead they went 'Well, sod this for a game of soldiers, I don't want to go to college, get a degree, get a good job and have a huge house, mortgage and 2.5 kids'. So then they'd started, you know, they started exploring alternatives, and as always happens with that a lot of people just spent a lot of time doing a lot of drugs, wandering round, getting fucked up, and trying to be enlightened. And of course a lot of them weren't enlightened, a lot of them ended up doing heroin, but a couple were, so it was well worth trying. (Ruth)

Other ways of life, then, are not imitated but rather used as a means of setting provisional goals for the project of self-development, for its reflexive implementation and for the discovery of appropriate contexts for both. Thus another participant used the American 1960s as a reference point for finding a reflexive lifeworld:

I suppose I had this idea in my head of coming across a kind of Merry Prankster-ish bunch of people who were interested in bouncing off each other as much as they could, rather than going to the pub. (Mark)

\section{Attitudes to movement projects}

Reflexivity, then, involves a certain distancing from customary expectations and a greater awareness of alternative possibilities. If it is taken to its logical conclusion, it naturally involves making some use of these: rather than reproducing existing social relations (albeit with an "ironic" awareness of their contingency), experimenting with alternatives, adopting a reflexive attitude not just in theory but also in practice.

I have already mentioned the variety of projects developed within this milieu (see Cox forthcoming for an institutional analysis of such milieux). Some of these projects are relatively successful, for a variety of internal and external reasons; others are stillborn or die rapidly. I am interested here in the cultural habitus, in the sense of a general orientation to the world, that 
enables this experimentation, that makes it possible to "try out" the implications of reflexivity. The best way of summarising this is seems to be in terms of a general valuation of creativity and "makeability", which as we have seen applies to the self as well as to the external world.

One way in which this habitus appears is in a fascination with form. This is of course a very visible feature of contemporary social movements, where the effort devoted to formulating and implementing an organisational form will often exceed the effort devoted to its ostensible purpose (cf. Melucci 1995). It also appears, however, in the enjoyment of simply playing with form and ideas, in the elaboration of purely verbal projects, the enjoyment of formalistic "mind games", and the "techie trip" of elegant and baroque technical activity. It can, of course, become the case that form takes over completely from content, or means from ends; this is undoubtedly part of the reason for the inordinate focus on rules and procedures that paradoxically plagues many movement institutions. If I am right, however, this is a necessary price for reflexive rationality.

One corollary of this experimental and playful attitude can be a lack of commitment. The world appears as a series of not entirely binding personal or collective projects and attempts at "getting things together", with a generalised expectation that different people will be "into" different projects at different times. Hence commitment has its costs:

Most people I know don't want to be committed to anything. Or anybody, because they're so desperate to get their lives together, get whatever it is that they want to do together that that takes up an awful lot of time, so they don't want to compromise that by being stuck in one place or one job or with one person or in one country. (Ruth)

In other words, "getting it together" - creative and reflexive activity in general - is potentially threatened by too great a degree of commitment to any specific project. The logical conclusion is that it is normal for participants to 
see the counter culture as something that is ultimately provisional and external, in other words, to maintain the reflexive attitude to the movement itself. As one participant comments:

It's kind of paradoxical to want to be part of a group and at the same time not yet part of the group. To want to create a comfortable subset or define its boundary or something. (Mark)

The lifeworld, then, is legitimated by its contribution to reflexive projects, and if it moves towards becoming "taken-for-granted" in its turn it needs to be ditched, and for the same reason it was initially entered. Thus it is always an open-ended exercise: too tight an articulation would defeat the purpose. The fascination with experimentation and the double-edged tolerance and refusal of commitment are ways of structuring interaction within this "free space", the skills of living together in a particular way. This may be formalised at times in particular institutions, but exists primarily as a way of doing things, a common "structure of feeling" geared towards reflexivity.

This has important costs for movement mobilisation. Not only is comitment only likely to projects that have strong personal value, but the lack of commitment to the milieu itself makes stable organisation difficult. Virtually all participants in this network have spent considerable periods of time abroad, for example; the very mobility that facilitates reflexive creativity also makes sustained involvement a difficult achievement. This is exacerbated by the tendency of social relationships to lose their reflexive edge and become "retraditionalised". One participant says of his decision to emigrate:

[The difference new people make is] new influences, new ideas. If I can be excused using a sort of Americanism clichZ̆, personal development, in the sense that my interaction with these people, whilst it is completely wrong to suppose that I can't get anything more out of interacting with these people, I had got caught in a rut, where my relationship with them was such that something had to change before I 
could get more out of my interaction with these people. That something needed to be other people bringing new attitudes, new ideas, fresh outlook on old ideas, anything, into it, would have possibly changed that and sort of got me out of that rut. (Josh)

Thus if lifeworld reflexivity and self-reflexivity are blocked by routinisation, "creativity" turns to "stagnation", and the likely response is to move on. But I want to argue that there are also other reasons why "creativity" is likely to generate "stagnation".

\section{The costs of reflexivity}

The principle of lifeworld reflexivity implies that all activity, not only work processes or political organisation, requires clear reasons and articulate decisions. Giddens (1994) has recently explored the pathological effects of the impact of reflexivity "from outside" on lifeworld contexts in the generation of compulsive and obsessional activity. What I am researching here, however, is a lifeworld where the demand for reflexivity comes very much "from within".

It is something of a sociological commonplace (e.g. Berger and Luckmann 1967) that routine, convention, tradition, ritual and so on are enabling mechanisms: they enable the regular production of action without much need for prior thought and discussion, they enable a sedimentation of "howto-do-it" knowledge and skill, and so on. For the same reason, of course, they privilege means rather than ends, exclude the operation of reason, reinforce local power structures, and prevent the exploration of new possibilities. Yet consider the implications of this critique.

If a reflexive orientation to the lifeworld demands a focus on ends and the elaboration and coordination of reasons for action, democratic agreement on the forms of activity, and the exploration of all the possibilities that can be imagined or read about by the educated and computer-literate in western 
societies in the 1990s, this makes activity of any kind an extremely demanding business.

The interest in other ways of life and other ways of thinking about the world, the fascination with form and technique, the interest in talking about impossible projects and so on then acquire another, immediately practical meaning, as ways of discovering problems in play and talk rather than in action and conflict. As one participant puts it:

It does help you if you've got a slight idea about something but it's vague, and you're really not that sure, and then you'll be sitting in a room with somebody who'll be talking about it and you'll go 'Yeah, that's it, that's exactly what I was looking for. Where is that?' Or 'What book was that in?' And they can tell you. [...] If you find somebody who's already done what it is that you're about to do you can get a lot of advice from them. You can get some pitfalls, as well. It's like 'I did this for ten years, and it's not worth it. Try something else instead.' (Ruth)

As this suggests, the stakes are high in contexts where neither the nature of the self, nor its goals, can be taken for granted, and the risks include criminalisation, homelessness, emigration and so on. Where reflexivity widens the range of actual options to include all possible choices, with no fixed yardstick to evaluate these possibilities and their consequences, choice becomes difficult, if not impossible. Choosing itself becomes an almost impossibly high barrier:

If you do have that amount of choice, if you sit down, like for instance, at the moment I'm in completely the ideal situation, because [...] I've got no ties whatsoever, I don't have to be back in Dublin for anything, I don't have to come back for a course, I don't have to come back for a job, I've got a job where I don't have a contract. I could leave tomorrow [...] my only limitations are money, that's the only thing. There's nothing 
else. Which is great. But it also means 'Oh no, what should I do next?'

Cause if you can do anything at all, it's difficult to narrow it down. (Ruth)

Given the costs of reflexive action, then, it is hardly surprising that life in this milieu alternates between bursts of enthusiastic activity and new projects which do fit the bill of reflexive creativity, and lengthy stretches of "null-space", of talk and play, of understructured inactivity. Thompson (1993) argued that such an alternation of intensive activity and relative inactivity was normal prior to the imposition of industrial labour discipline; its reflexive variant, however, carries with it an alternation between elation and depression that was presumably foreign to the annual agricultural cycle.

The difference between this and the motivational structure of unreflexive contexts is brought out in the following comment:

At the moment he's still officially temporarily employed by [a removals firm], which he has said himself is doing him an absolute world of good in that there is a degree of externally imposed discipline which has a knock-on effect in that he's able to achieve whatever the hell he wants to do, he values his spare time, he uses it efficiently, he gets things done, whereas previously he had so much bloody time to do anything he achieved nothing. (Josh)

For those few activists who overcome the barriers of action on a regular rather than sporadic basis without such external constraints, this is achieved at a very high cost, that of forcing themselves into action, and resolving the difficulties of choice and commitment by placing themselves under extreme moral pressure. The levels of burnout among such activists are then very high, since the amount that needs doing is effectively infinite once reflexivity is applied to one's political persona, and because reflexive modes of organising are not just extremely labour-intensive but also 
extremely emotional, since they place one's own personal project continually in question and depend on self-exploitation and the mining of this very insecurity.

This can be seen as an additional reason why movement institutions commonly suffer from what Raschke (1993) identifies as a conflict between legitimacy and efficiency. The reflexive attitude is highly legitimate but not particularly efficient. Goal-rational behaviour is illegitimate in terms of both reflexivity and autonomy. Those activists who see the need for goal-rational behaviour commonly suffer, along with the well-known problems faced by all political activists, from a lack of identification with the way in which they need to behave in order to achieve their aims: an acute form of the Weberian paradox.

\section{Local rationalities and movement milieux}

These local rationalities are initially formed in the specificities of movement milieux. Thus one participant comments of a student occupation that it set

a framework of the way in which the social interactions that that particular group of people have subsequently continued to use: a lot of music, people sitting round playing music, talking, often about trivia, but there have often been, you know, good serious discussions as well. (Josh)

The resources for the development of autonomy and reflexivity, such as books or music (see Cox 1997), are made available through the networks of these milieux:

There's a very laid back attitude to property. People are not particularly possessive or protective of what is their property, you know, people borrow things from, there's an awful lot of kipple that transfers and ends up in various flats. It's not uncommon to arrive in somebody's flat, 
'Oh, can I have a look through your tapes?' - 'Yeah, sure, go for it.' - 'Oh fuck, that's mine, where'd you get that?' - 'I dunno, oh, take it back.' 'Oh yeah, well haven't seen that in years'. You know, people don't get wound up about it, they just 'Ah shit, I haven't seen that, I was wondering where it went'. (Josh)

Thus the local rationalities we have examined are formed within milieux structured by very specific cultural assumptions, as another participant stresses:

The only philosophy I thought that was behind all that group of people was, you know this thing, 'What goes around comes around', you know, the idea of like, at a simple level, somebody bums a cigarette off you, you bum a cigarette off somebody else? This kind of thing, at a really low level, but it's true, what goes around comes around. You do things for people, the idea is, instead of, I was brought up with a favours system, you know, I do this for you therefore you have to do this for me. Somebody gives you a Christmas present, you're morally obliged to give them one, this kind of thing, whereas I just liked that, you know, that people would do things for other people for no apparent reason. It's like, I have something that I don't need. You need it, take it. (Ruth)

The net effect of this cooperation with each other's projects of autonomy is a reflexive lifeworld built on strong personal links:

I think it was like a support group. It was one of the closest groups of people I ever came across. I hadn't come across groups of people who knew each other that well and were that close, which was really nice. Knew everything about each other, had been through lots together. (Ruth)

These socially organised practices enable an apparently individualistic mode of life to maintain its separate identity. There is a close relationship in this 
milieu between individuals' continued participation in such practices and the networks that sustain them, and their continued development of personal and lifeworld reflexivity. At the same time, these practices support rationalities that are capable of abstraction and generalisation far beyond these contexts.

I have suggested that a concept of local rationality can bridge the gap between the sociocultural basis of contemporary movements, their characteristic modes of formation, and their impact on the wider society. The implication is that we could consider individualisation and the development of reflexivity (Giddens 1990, Beck et al 1994) not as a structural feature of high modernity reflected in contemporary movements, but as a rationality formed within movement milieux. The suggestion that contemporary social movement milieux are a key source of cultural change (Lash and Urry 1987, Lash 1994a, 1994b, Sulkunen 1992) would then be directly analogous to Weber's arguments about the cultural roots of modernity (1958). This leaves open the question of how such rationalities are generalised beyond their sources. Before dealing with this, I want to return to the ways in which we interpret social movements.

\section{Hidden discourses}

If social movements, and their milieux, operate under very specific cultural assumptions, researchers who fail to take this explicitly into account will misread much of what they see in terms of their own taken-for-granted assumptions. Despite some honourable exceptions (Diani and Eyerman 1992), much movement research is unreflexive in this specific sense of failing to thematise - and hence notice - differences in culture. The problem is reinforced if there is a correspondence of the point of view of researchers with that of some participants. The still-dominant academic construction of movements as primarily political, and the corollary of research on the visibly 
political aspects of movements, is likely to be shared by the most politically active and organised among their movement contacts, and both can collude in this perception of movement as politics. But what if, as we have seen, the committed activist is a rather unusual figure, and if their attempts at mobilisation render the cultural logics of other participants opaque to them?

There might then be some value in examining how those other participants view mobilisation. This can be illustrated by the example of a student occupation. Reflecting on that, one participant says:

I think most people realistically were in the occupation because it was damn good fun. To me, from my perspective, politics is something that, and I think it's reasonably common within this group of people, politics is an interest, but not the driving force, and those for whom it is the driving force, such as Se $\$ n$ and Muireann, are now very much peripheral to the group. (Josh)

Another agrees:

Obviously, the whole thing was politically motivated, but once you got in there you were, I spent quite a lot of time in there at the start of it, that you had a lot of time to fill, that, you know, you had your time when you were doing things and where you were just basically hanging round with the other people who were there all the time, and getting to know them intimately and getting introduced to things that you hadn't been introduced to before. (Joe)

While participants are aware the other logics of the full-time activists, they respond to them in terms of the perspective I have already outlined, of a reflexive milieu made up of a series of projects, to which people respond in terms of their own rationality:

I remember sitting in the Coffee Inn, and Pat gave everybody a conker, for some weird reason, and we were sitting in the Coffee Inn with these weird plans for building this windmill in Dermot's back garden, and 
Harry had this kind of odd plan for world domination, trying to [laughter] bring the Sixties back to Dublin because they'd never really hit, which I remember I kind of went 'Well, OK, that's weird, but I've nothing better to do for the summer and [laughs] it might be fun.' (Ruth)

Thus the hidden discourses of ordinary participants coincide with Melucci's position of seeing movement action as simply one part of a broader way of life for the majority of those involved. Participants are fully capable of inserting political action into their own local rationalities, and of making links between the two:

There were a lot of discussions going on about what was happening and what people were trying to do and stuff. I wasn't really all that involved in many of those. And I don't think I was at any of the big sort of decision meetings. If anything, I was sort of a hanger-on rather than seriously involved in it [....] I was in the party end of it, and one of the things that people there were trying to do was make sure that there was sort of a minimum number of people around, so as not to give security an opportunity to come in en masse and throw everybody out, and I certainly would have been there as cannon fodder in that sense, but really just another face more than anything else. (Josh)

The potential tension between the instrumental rationalities of the "system" and the local rationalities of the lifeworld is then also a key element in people's attitude towards political action. If researchers are not alive to this cultural context, they will see only organisation and the difficulties of organisation.

Much of the literature, however, offers an uncritical (because implicit) identification by researchers with movement organisers. There is of course a parallel between their situations: both are intellectuals, in the sense that both are engaged in the theoretical construction of a "movement" as an essentially political entity, and both are involved in the organisation of social 
relations (of mobilisation, of research) which attempt to involve other participants as part of this political entity.

Yet committed activists (like researchers) are a rather small minority within the networks of those they (occasionally) mobilise, and form only one element, albeit an important one, of movement milieux. A focus on the most active, organised and articulate elements of the lifeworld is in some ways a focus on its least characteristic elements, and on those which are in some important ways least different from the dominant lifeworld: participants who have held formal positions in political organisations, for example, are those who are most likely to have followed conventional career paths in other respects. Not only is the researcher in a similar situation to the activist, but the activist may also be closer to the researcher's lifeworld than many other participants.

This is not to argue that only the most inarticulate and disorganised of participants can speak for movements. It is to say that researchers who fail to notice the double hermeneutic, whereby movement cultures are both other than those of the dominant culture and divided between those engaged in their instrumental rationalisation (for political or indeed economic reasons) and those for whom local rationalities prevail, are very likely to systematically misread what is going on in the far more stable milieux from which movement mobilisations occasionally grow. A fully reflexive sociology of the broader movement, by thematising these issues, might make it possible to move beyond this self-confirming situation.

\section{Conclusion: theorising movement milieux}

Movement milieux, then, are reflexive lifeworlds where the local rationalities

I have described are developed, explored, (partially) institutionalised and from which they may be generalised. This can be phrased in terms of Eyerman and Jamison's definition of a social movement as "a cognitive 
territory" (1991: 55), of Wainwright's (1995) analysis of movements as engaging in a grassroots politics of knowledge, or in Gramsci's (1991) concept of intellectual activity as at once "theoretical" and "directive" (organising) activity. The local rationalities of movement milieux then appear as the rethinking and reorganisation of everyday life from below. This naturally comes into constant conflict with the instrumental rationalities of capital and the state, within the lifeworld but also within the individual.

This everyday conflict is then a "war of position", in Gramsci's metaphor - a struggle over power relations within the social relations of "civil society" (and the "soft" fringes of the welfare state), rather than the "war of movement" represented by direct challenges to the coercive core of the state. The construction of hegemony, or the articulation of counter-hegemony, are precisely this practical extension or repulsion of these different rationalities within everyday lives, as agents attempt to structure lifeworld contexts in terms of one or the other. It is in this active way that a formal rationality can be generalised beyond its original lifeworld context, and that social movements can be seen as cultural challenges.

Within contemporary capitalism, groups such as the unemployed and students are "decommodified" (Offe 1985): they are temporarily or permanently marginalised from the production process and its associated structures of domination. From Berger et al. (1974) to Bey (1995), this situation has been identified as an important site for the generation of cultural resources for challenges to the dominant forms of late modernity. In particular, autonomy and reflexivity seem "locally rational" responses to this relative weakness of direct domination.

Such lifeworlds, then, are neither simply passive victims of radical modernity nor locations of purely defensive struggles against colonisation by instrumental rationality: their own local rationalities are capable of communicative rationalisation to a point where they can break the bounds 
of the lifeworld and spread to others. Whether they succeed in doing this is of course a question of the politics of culture.

In western states since 1968 , that challenge to previously "taken-forgranted" modes of cultural domination has since been met with responses geared to enabling a resumption of "business as usual". If Touraine (1981) is right in identifying struggles over ñhistoricityî as definitive of social formations, then the shift from ñorganisedî to ñdisorganisedî capitalism is a shift from a "struggle over closure" (between the dominant "old right" and subordinate "old left") to a "struggle over openness", in which the conflict between the dominant forces of disorganised capitalism and the subordinate "new left", or the counter culture, over just how far openness (reflexivity, autonomy) is to be taken, defines the new stakes at issue, and marginalises other forces.

Reflexivity tends to mean a situation where social relations are "consumed" reflexively, but "produced" unreflexively; in other words, a diversity of "negotiated" readings, which represents a precondition for effective cultural hegemony - the ability of the dominated to find their own value in the cultural construction of their own domination (Gramsci 1991: 12 - 14). Similarly, autonomy tends to mean a situation of atomisation, possessive individualism and goal-rational action. The local rationalities of the counter culture can radicalise both towards an active lifeworld reflexivity which applies to the actual production of social relations as much as to the attitudes adopted towards them, and towards a reflexive autonomy which does not restrict itself to the pursuit of given goals.

The conflict is then precisely over the practical meanings of reflexivity and autonomy: whether they can form part of a new hegemony to contain social conflict, geared around instrumental rationality, or whether they can be radicalised to the point of rupture within the kinds of local rationality I have been describing. McKay (1996) asks why the British state has adopted such 
a brutal strategy against the free festival scene, the New Traveller lifestyle, rave culture and so on, and notes the paradox that these groups are among the most ñenterprisingî representatives of ñpersonal initiativeî and ñindividual freedomî. Perhaps this paper offers a pointer to the answer.

${ }^{\mathrm{i}}$ I want to thank the participants for the interviews this chapter is based on, and Hilary Tovey and Anna Mazzoldi for comments on earlier versions. 


\section{Bibliography}

Beck, Ulrich, Giddens, Anthony and Lash, Scott

1994 Reflexive modemisation. Cambridge: Polity.

Berger, Peter and Luckmann, Thomas

1967 The social construction of reality. London: Allen Lane, 1967.

Berger, Peter and Brigitte and Kellner, Hansfried

1974 The homeless mind. Ha mondsworth: Penguin.

Bey, Hakim

1991 TAZ Brooklyn: Autonomedia

Cox, Laurence

1997 "Reflexivity, social transformation and counter culture". In Colin Barker and Mike Tyldesley (eds.), Third intemational conference on altemative futures and popular protest (vol. 1). Manchester: Manchester Metropolita n University.

Forthcoming "Towards a sociology of counter cultures?" In Emma McKenna and Roger O'Sullivan (eds.), Cultural diversity in modem Ireland. Aldershot: Avebury.

Diani, Mario

1992a "The concept of social movement".Sociological Review (40/1): 1 - 25.

1992b "Analysing social movement networks". 107 - 135 in Mario Diani and Ron Eyeman (eds.), Studying collective action. London: Sage.

Diani, Mario and Eyeman, Ron (eds.)

1992 Studying collective action. London: Sage.

Eder, Klaus

1985 'The 'new social movements'." Social Research (52): 663 - 716.

1993 The new politic s of class. London: Sage.

Eyerman, Ron and J amison, Andrew

1991 Social movements. Ca mbridge: Polity.

Giddens, Anthony 
1990 The consequences of modemity. Ca mbridge: Polity.

1994 "Living in a post-traditional society." 56 - 109 in Ulrich Beck, Anthony Giddens and Scott Lash, Reflexive modemisation. Cambridge: Polity.

Gramsci, Antonio

1971 Selections from Prison Notebooks. London: Lawrence \& Wishart.

1991 Il ma terialismo storico e la filosofia di Benedetto Croce. Roma: Riuniti.

Habermas, JÙrgen

1984 The theory of communic ative action (vol. 1). Lond on: Heinemann.

1987 The theory of communic ative action (vol. 2). Ca mbridge: Polity.

Hradil, Stefan

1987 Sozia Istrukturanalyse in einer fortgeschrittenen Gesellsc haft. Opla den: Leske \& Budrich.

Lash, Scott

1994a "Reflexivity and its doubles ". 110 - 173 in Ulich Beck, Anthony Giddens and Scott Lash, Reflexive modemisation. Cambridge: Polity.

1994b "Expert-systems or situated interpretation? " 198 - 215 in Ulich Beck, Anthony Giddens and Scott Lash, Reflexive modemisation. Cambridge: Polity.

Lash, Sc ott \& Umy, J ohn

1987 The end of organised capitalism. Cambridge: Polity.

McKay, George

1996 Senseless acts of beauty. London: Verso

McLennan, Gregor

1981 Marism and the methodologies of history. Lond on: New Left Books.

Melucci, Alberto

1985 "The symbolic challenge of contemporary movements." Social Research (52):

$789-816$.

1989 Nomads of the present. London etc.: Hutchinson.

1992 L'invenzione del presente. Bologna: Il Mulino (2nd edition). 
1995 "The new social movements revisited ". 107 - 119 in Louis Maheu (ed.), Social movements and social c lasses. London: Sage.

MÙller, Dagmar

1990 'Zur Rekonstruktion von Habitus - 'Stammb?umen' und Habitus 'Metamomhosen' der neuen sozialen Milieus." Forschungsjoumal neue soziale Bewegungen (8/ 3): $57-65$.

Offe, Claus

1985 "New social movements ". Social Resea rch (52): 817 - 868.

Ra schke, J oa chim

1985 Soziale Bewegungen. Frankfurt (M): Campus.

1993 Die G rÙnen. K? In: Bund-Verlag.

Sulkunen, Pekka

1992 The European new middle class. Aldershot: Avebury.

Thompson, E P.

1993 Customs in common. Hamondsworth: Penguin.

Touraine, Alain

1981 The voice and the eye. Cambridge: Cambridge UP.

1985 "An introduction to the study of social movements." Social Research (52): 749 788.

Vester, Micha el, v. Oertzen, Peter, Geiling, Heiko, et al.

1993 Sozia le Milieus im gesellsc haftlic hen Strukturwandel. K? In: Bund.

Wagner, Peter

1994 A sociology of modemity. London / New York: Routledge.

Wa inwright, Hilary

1994 Arguments for a new left. Oxford: Blackwell.

Weber, Max

1985 The protestant ethic and the spirit of capitalism. New York: Sc ribner's.

1984 Soziologisc he Grundbegriffe. TÙbingen: Mohr. 